\title{
Coordinated Stability Control of Wind-Thermal Hybrid AC/DC Power System
}

\author{
Zhiqing Yao, ${ }^{1}$ Zhenghang Hao, ${ }^{2}$ Zhuo Chen, ${ }^{2}$ and Zhiguo Yan $^{3}$ \\ ${ }^{1}$ School of Electrical and Electronic Engineering, Huazhong University of Science and Technology, Wuhan 430074, China \\ ${ }^{2}$ School of Electrical Engineering, Guizhou University, Guiyang 550025, China \\ ${ }^{3}$ School of Electrical Engineering and Automation and Key Laboratory of Pulp and Paper Science e \\ Technology of Ministry of Education of China, Qilu University of Technology, Jinan 250353, China
}

Correspondence should be addressed to Zhiguo Yan; yanzg500@sina.com

Received 12 August 2015; Accepted 16 September 2015

Academic Editor: Xinguang Zhang

Copyright (C) 2015 Zhiqing Yao et al. This is an open access article distributed under the Creative Commons Attribution License, which permits unrestricted use, distribution, and reproduction in any medium, provided the original work is properly cited.

\begin{abstract}
The wind-thermal hybrid power transmission will someday be the main form of transmitting wind power in China but such transmission mode is poor in system stability. In this paper, a coordinated stability control strategy is proposed to improve the system stability. Firstly, the mathematical model of doubly fed wind farms and DC power transmission system is established. The rapid power controllability of large-scale wind farms is discussed based on DFIG model and wide-field optical fiber delay feature. Secondly, low frequency oscillation and power-angle stability are analyzed and discussed under the hybrid transmission mode of a conventional power plant with wind farms. A coordinated control strategy for the wind-thermal hybrid AC/DC power system is proposed and an experimental prototype is made. Finally, real time simulation modeling is set up through Real Time Digital Simulator (RTDS), including wind power system and synchronous generator system and DC power transmission system. The experimental prototype is connected with RTDS for joint debugging. Joint debugging result shows that, under the coordinated control strategy, the experimental prototype is conductive to enhance the grid damping and effectively prevents the grid from occurring low frequency oscillation. It can also increase the transient power-angle stability of a power system.
\end{abstract}

\section{Introduction}

As one of the most efficient new energy sources that have the potential of large-scale development, wind power generation has developed speedily in China. Due to the limited ability of electricity consumption, wind power in northwest China, northeast China, and north China should be transmitted to the load center by long-distance transmission line $[1,2]$. Given that wind power is not constant and it is not economical to transmit wind power alone, there arises the necessity to "bond" large-scale wind farms with thermal power plant so as to realize transregional transmission. However, hybrid transmission system easily triggers low frequency oscillation or angle instability $[3,4]$.

Damping features and controllable strategy of flywheel energy storage device [5], flexible power conditioner [6], and static series compensator [7] were studied to improve damping of the power system in previous research. But the cost of large-scale power electronic equipment is so high that it limits the application. In comparison, doubly fed wind generator can realize decoupling control of active and reactive power [8]. Excitation converter in the wind turbine system can be adjusted to control the active power in the transient process. As a result, for large-scale wind farms, active power in the whole wind farms can be adjusted randomly and quickly through the communication network, making the wind farms controllable. So long as the active power is able to be adjusted, it is possible to enhance the stability of the power system. Controllable power in the wind farms can not only help increase the damping and prevent low frequency oscillation, but also enhance transient angle stability of the power system, which is meaningful for ensuring grid safety.

In this paper, firstly, structural features of hybrid power system of wind farms and thermal power plant are analyzed and problems about stability of the power transmission system are pointed out. Secondly, the mathematical model of 


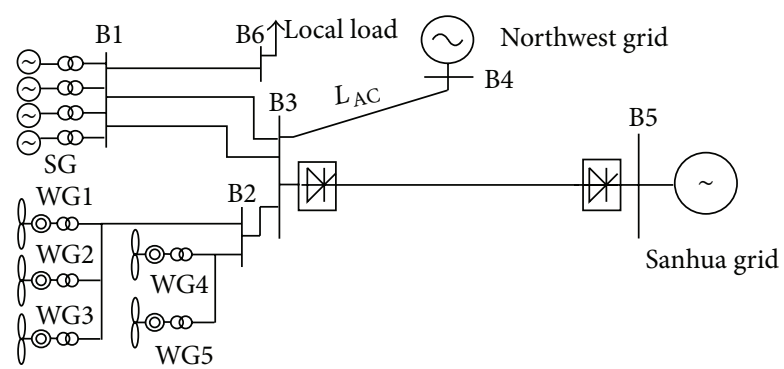

FIGURE 1: AC/DC power system with wind farms incorporated.

doubly fed wind farms and DC power transmission system is established. And it is proved that active power in the largescale wind farms is controllable. Thirdly, for the purpose of increasing damping of the system and enhancing angel stability, a coordinated control strategy for wind farms and DC power transmission system is proposed. Finally, the experimental prototype is made and the control effect of the experimental prototype is also introduced in detail.

\section{AC/DC Power Transmission System Incorporating Wind Farms}

Chinese large-scale wind farms are usually located at remote areas. Due to small load capacity, power generated by the large-scale wind farms cannot be consumed. So long-distance transmission is an inevitable solution. But as the wind power is not constant, long-distance transmission is costly if wind power is the only thing to transmit. And irregular fluctuation of the wind power would make the grid unstable. So, at the present time, a hybrid transmission mode of wind farms and thermal power plant (also named as wind-thermal hybrid power system) [9] is the main form of transmission, as is shown in Figure 1. To be more specific, wind farms are connected with the thermal power plant nearby and the power is transmitted to other areas by extra high voltage (EHV) line.

Wind-thermal hybrid power transmission mode is for long-distance transmission. But as the utilization hours of wind power are lesser than the conventional thermal power plant, the transmission channel capacity of wind power is designed lower than the maximum power. When large-scale wind power is generated, the transmission line will be heavily loaded, and the thermal power plant also functions in a heavy-load state, resulting in low frequency oscillation. In addition, vector control of the turbine may pose influence on damping [10]. It is also worth noticing that the thermal power unit bonded with the wind farms is responsible for curbing wind power fluctuation. So the adjustment for the unit is frequent, which would damage the power system stabilizer (PSS) [11] and hamper damping characteristic. Therefore, effective measures on damping should be taken to ensure safe operation of the wind-thermal power transmission system.

In addition, the wind-thermal hybrid power system does not work in a conventional way. The dynamic behaviors of wind farms may weaken the angle stability of the thermal power plant, even the whole power system. Thus, the wind farms and the AC/DC power transmission system should be subjected to coordinated control in order to erase negative effect caused by the wind farms.

\section{Mathematical Model for Wind-Thermal Hybrid Power Transmission}

3.1. Wind Turbine System. The mechanical part of the wind turbine system includes wind turbine, transmission shaft, and gearbox. Wind turbine is used to capture wind energy through the turbines and transform it to the mechanical torque on the wheel hub. The shaft and gearbox is used to pass the driven force of the wind turbine to the generator and increase the revolving speed. The gear ratio can reach 100. To simplify calculation, the mechanical part is regarded as a concentrated mass expressed by first-order inertial element [8]:

$$
\frac{\mathrm{d} P_{m}}{\mathrm{~d} t}=\frac{1}{T_{d}}\left(P_{T}-P_{m}\right),
$$

where $P_{m}$ and $P_{T}$ refer to mechanical power and electromagnetic power, respectively, on the rotor of the generator. $T_{d}$ refers to inertia time constant.

3.2. Mathematical Model for DFIG. DFIG is actually the rotor asynchronous motor. There are symmetrical three-phase windings on the stator and the rotor. The modeling process is similar to that of asynchronous motor and synchronous generator, in which the primitive equation is confirmed in the three-phase static coordinate system and then coordinates are transformed. Unlike the modeling of synchronous generator, $d q$ coordinates of DFIG can be oriented in different modes, such as stator flux mode, rotor flux mode, and stator voltage mode. And orientation of $d q$ coordinates of synchronous generator is only to take physical location of the rotor. In this paper, the stator vector voltage of DFIG is taken as axis $q$. In the $d q$ coordinates system, the stator flux $\left(\psi_{d s}, \psi_{q s}\right)$ and rotor current $\left(i_{d r}, i_{q r}\right)$ are taken as the state variables. The state equation is expressed as follows [11]:

$$
\begin{aligned}
& p \psi_{d s}=-\frac{r_{s}}{l_{s}} \psi_{d s}+l^{\prime \prime} r_{s} i_{d r}+\omega_{1} \psi_{q s}, \\
& p \psi_{q s}=-\frac{r_{s}}{l_{s}} \psi_{q s}+l^{\prime \prime} r_{s} i_{q r}-\omega_{1} \psi_{d s}+u_{q s}, \\
& p l^{\prime} i_{d r}=-r_{r} i_{d r}+u_{d r}+\omega_{s} l^{\prime} i_{q r}+\omega_{s} l^{\prime \prime} \psi_{q s}-l^{\prime \prime} p \psi_{d s}, \\
& p l^{\prime} i_{q r}=-r_{r} i_{q r}+u_{q r}-\omega_{s} l^{\prime} i_{d r}-\omega_{s} l^{\prime \prime} \psi_{d s}-l^{\prime \prime} p \psi_{q s},
\end{aligned}
$$

where $l^{\prime}=\left(l_{r}-l_{m} l_{m} / l_{s}\right)$ and $l^{\prime \prime}=l_{m} / l_{s}, l_{s}, l_{r}$, and $l_{m}$ being stator self-inductance, rotor self-inductance, and mutual inductance, respectively; $r_{s}$ and $r_{r}$ are stator and rotor resistance, respectively; $\omega_{1}$ and $\omega_{s}$ are synchronous speed and slip, respectively; $u_{d r}$ and $u_{q r}$ are vertical and horizontal vector of excitation, respectively; $u_{q s}$ is stator voltage; and $p$ is differential operator.

3.3. UHVDC Power Transmission System Model. UHVDC power transmission refers to DC transmission based on thyristor inverter. It consists of the inverter, DC line, and 
the auxiliary equipment $[12,13]$. Quasi steady state model is used to simulate the UHVDC primary system. DC commutation is described by algebraic equation. DC line and smoothing reactor are described in the T-equivalent-circuit model [14-16]. Substitute the algebraic equation for the differential equation and get the mathematical model for UHVDC power transmission system expressed by $[17,18]$

$$
\begin{aligned}
I_{d r} & \\
\quad & =\frac{1}{L_{d r \Sigma}}\left(-R_{d} I_{d r}-U_{c}+\frac{3 \sqrt{2}}{\pi} U_{d r} \cos \alpha-\frac{3}{\pi} X_{r} I_{d r}\right), \\
I_{d i} & =\frac{1}{L_{d i \Sigma}}\left(-R_{d} I_{d i}-U_{c}+\frac{3 \sqrt{2}}{\pi} U_{d i} \cos \beta-\frac{3}{\pi} X_{i} I_{d i}\right), \\
U_{c} & =\frac{1}{C}\left(I_{d r}-I_{d i}\right),
\end{aligned}
$$

where $I_{d r}, I_{d i}$, and $U_{c}$ are state variable. $I_{d r}$ and $I_{d i}$ are DC current of rectifier and inverter; $U_{c}$ refers to the voltage in the middle of DC line; $R_{d}$ is direct current resistance; $C$ is earth capacitance equivalent to DC line; $U_{d r}$ and $U_{d i}$ are DC voltage of rectifier and inverter; $L_{d r \Sigma}$ and $L_{d i \Sigma}$ are equivalent inductance of rectifier and inverter; $X_{r}$ and $X_{i}$ are commutation reactance of rectifier and inverter; and $\alpha$ and $\beta$ are trigger delay angle of rectifier and trigger angle of inverter.

\section{Conditions for Quick Adjustment of the Wind Farms}

4.1. Quick Adjustment of the Active Power of Single Turbine in Transient Process. Before the wind farms realize the effectively quick adjustment, it is made sure that every turbine is highly controllable. From (2), the rotor current can be controlled by rotor voltage. But $i_{d r}$ and $i_{q r}$ are cross-coupled, so feedforward compensation scheme is usually adopted to realize decoupling control. The feedforward compensation is calculated from rotor current and internal flux variables:

$$
\begin{aligned}
& e_{d r}=k\left(\omega_{s} l^{\prime} i_{q r}+\omega_{s} l^{\prime \prime} \psi_{q s}\right), \\
& e_{q r}=-k\left(\omega_{s} l^{\prime} i_{d r}+\omega_{s} l^{\prime \prime} \psi_{d s}\right) .
\end{aligned}
$$

Add $e_{d r}$ and $e_{q r}$ to $u_{d r}$ and $u_{q r}$, and get the new control variable. For the state equation of rotor current in (2), substituted feedforward compensation item, the relationship between rotor current and control command $\left(u_{d r}^{*}, u_{q r}^{*}\right)$ is

$$
\begin{aligned}
& p L^{\prime} i_{d r}=-r_{r} i_{d r}+u_{d r}^{*}, \\
& p L^{\prime} i_{q r}=-r_{r} i_{q r}+u_{q r}^{*} .
\end{aligned}
$$

Equation (5) shows that the response of active current and reactive current to the control command is the first-order inertial link. Time constant of inertial element is $\tau$. Typical parameters of DFIG are substituted into $\tau$ and we can get it is about $10 \mathrm{~ms}$. This means that the single turbine can respond at the level of ms under external control command.
4.2. Quick Adjustment of the Active Power of Wind Farms in Transient Process. In the previous research, the wind farms were usually equaled to a single wind turbine $[8,11]$. Obviously, they are different. Section 4.1 has already proved that the single turbine can respond at the level of ms, but whether this holds true to the wind farms still needs to be proved.

A large-scale wind farm has hundreds of wind turbines. Controlling them depends on wide-field communication technology. The control system of the wind farms has a master-slave structure. There are two methods of communication: (1) one-to-multiple answering transmission and (2) one-to-multiple global broadcast. For method (1), as all turbines (200 sets) are slave turbines, it means 200 messages are sent in a controlling cycle. For method (2), as every turbine receives the same message, only 1 message is sent in a controlling cycle.

Message transmission presents the following features: suppose the length of the message is 200 bits and the serial communication baud rate is $1 \mathrm{Mbps}$. It is calculated that it costs $0.2 \mathrm{~ms}$ to send the message. If fiber communication is adopted for long-distance transmission, $1.5 \mathrm{~ms}$ should be used in photovoltaic conversion. So the total time which is the delay time of the fiber communication for long-distance transmission is $1.7 \mathrm{~ms}$. Therefore, time delay in a controlling cycle in method (1) is $200 \mathrm{~ms}$ and that in method (2) is $1.7 \mathrm{~ms}$. Obviously, method (2) is suggested as $1.7 \mathrm{~ms}$ time delay will not pose significant influence on the closed-loop control system.

According to the analysis in Sections 4.1 and 4.2, based on global broadcast fiber communication technology, the wind farms can be an active power source which is able to be adjusted quickly.

\section{Coordinated Control Strategy of Wind Farms and DC Power Transmission System}

5.1. Basic Ideas and Purposes of Coordinated Control. Even though it may weaken the damping of conventional power plant and angle stability when the wind farms are connected with the thermal power plant, the ability of power adjustment of the wind farms would increase the damping of synchronous generator and enhance angle stability. Basic ideas of coordinated control of wind farms and DC power transmission system are mainly described as follows: the revolving speed or the frequency of synchronous generator of the conventional power plant is fed back to the controller; then the controlled quantity that can activate small-scale dynamic active power in the wind farms is produced through gain calculation and phase correction; and the dynamic active power of the wind farms propels the synchronous generator to produce electromagnetic torque with damping characteristic. So the damping can be increased and oscillation can be restrained. The key to supply the synchronous generators with the positive damping is that the wind farms must be controllable and can be controlled quickly.

5.2. Technical Framework of Coordinated Control. Based on the controllability of the wind farms and DC transmission system, the damping control principle of the thermal power 


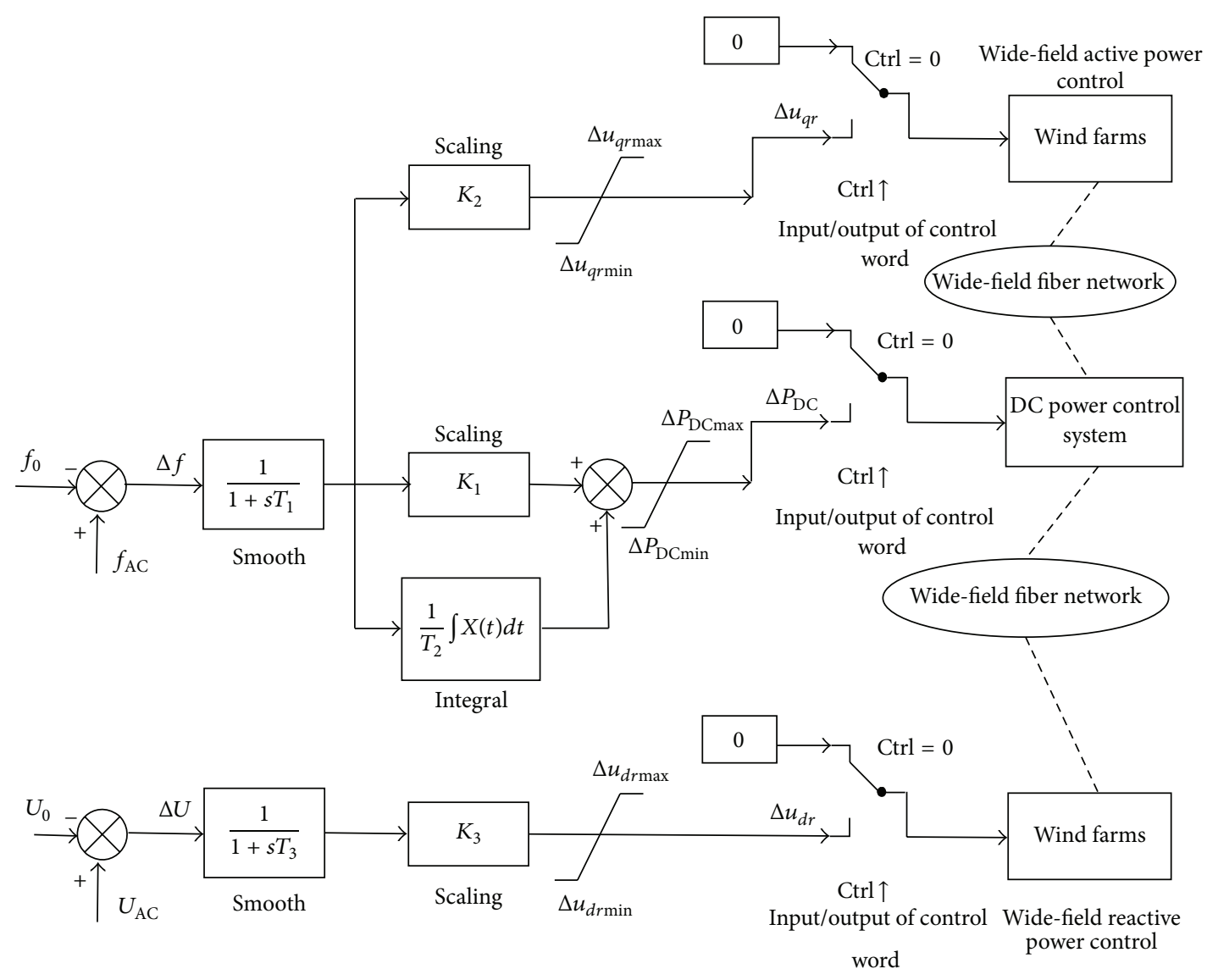

FIGURE 2: Coordinated control strategy framework.

plant is described in Figure 2. Firstly, the frequency of common DC-bus of the wind farms $\left(\Delta f_{p c c}\right)$ or speed or angle of the synchronous generator is collected. Secondly, the collected signal passes smooth block and scaling block and integral link. Then the controlled signal of the $i$ th wind turbine $\left(\Delta u_{\text {gri }}\right)$ is confirmed according to its working state and the allocation algorithm. This controlled signal is sent to the active circuit of each wind turbine through wide-field fiber communication network (excitation voltage reference point at axis $q$ of $d q$ decoupling control of the excitation converter) so that the wind turbines can adjust the active power synchronically. As a result, the active power in the transient process can increase the damping of the synchronous generator and prevent low frequency oscillation.

Parameter design of damping controller is expressed as follows: the value of $T_{1}$ is set up under the condition that the low frequency signals are able to pass through; and the angle for compensation is figured out by calculating the dynamic frequency before adjustment and the values of $T_{2}$ and $T_{3}$ are calculated; based on these values, the value of $K$ is confirmed according to the expected dynamic frequency.

When the power transmission system is disturbed, the most important thing is to extract fault characteristic quantity and analyze the type and the place of the fault, in other words, to judge whether it occurs in the DC system or the AC system. If the fault occurs in the DC system, DC block results in the great reduction of power. At this moment, the active output of the wind farm should be lowered within controllable time to protect the synchronous generator from instability. And the reactive output is captured to prevent abrupt rise of the voltage and the instability of the wind turbine.

When the fault occurs in the AC system, the power reduces substantially. The output power of the DC system should be increased within set time. But the sudden supply of DC power may increase the demand of reactive power and decrease AC bus voltage at the converter station. Thus, the reactive output of the wind farms should be adjusted quickly to prevent voltage fall. At the same time, the reactive power demand in the transient process is calculated according to the output power of DC system and the reactive power is sent from the wind farms.

\section{Modeling and Prototype Test Based on RTDS}

An experimental prototype is designed according to the coordinated control strategy framework mentioned in Section 5.2. To test the coordinated control strategy and verify the effectiveness of the experimental prototype, "hardware in-theloop simulation" is conducted. The experimental prototype is the real object and the wind-thermal power transmission system is the visual object based on Real Time Digital System (RTDS). 


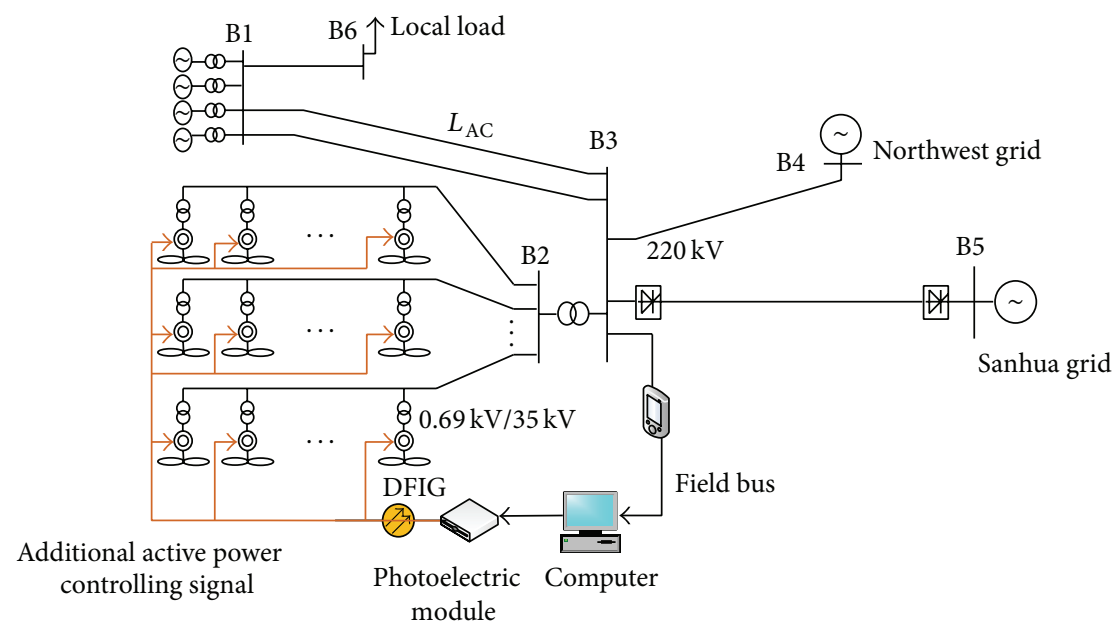

FIGURE 3: Simulation case.

6.1. Simulation of the Wind-Thermal Power Transmission System. The wind-thermal power transmission system is simulated and tested, as shown in Figure 3. Compared to the conventional power plant, each wind turbine has small capacity and the wind farms have a large number of wind power units [19]. It is impossible to simulate every turbine set [14]. Therefore, "equivalent similitude ratio" method is adopted in the simulation. In other words, the large-scale wind turbine system is replaced by a relatively small DFIG in which there are many wind turbine sets closely related to each other. Parameters are scaled down to a proper proportion. Thus, a largescale wind farm is divided into sections and each section is simulated by DFIG. As a result, electromagnetism and transient process can be better reflected and the process is simplified to make the simulation close to the real situation.

The proposed wind-thermal power transmission system model based on RTDS consists of six wind turbines and one synchronous generator set. Wind-thermal capacity is in ratio of $1: 1.5$. According to the principle of "equivalent per-unit value of parameter," the capacity of the synchronous generator is scaled down to the level of MW. The rated capacity of a DFIG is $2.2 \mathrm{MVA}$ and the rated frequency is $60 \mathrm{~Hz}$.

In Figure 3, parameters of the DFIG are as follows: stator winding resistance is 0.00462 p.u., stator leakage inductance is 0.102 p.u., rotor winding resistance is 0.00736 , rotor leakage inductance is 0.11 p.u., and stator and rotor mutual inductance is 2.62 p.u.; parameters of synchronous generator are (refer to literature [16] for name and physical definition)

$$
\begin{aligned}
& x_{d}=0.51 \text { p.u., } \\
& x_{d}^{\prime}=0.042 \text { p.u., } \\
& x_{d}^{\prime \prime}=0.032 \text { p.u., } \\
& x_{q}=0.375 \text { p.u., } \\
& x_{q}^{\prime \prime}=0.011 \text { p.u., } \\
& T_{d}^{\prime}=0.33 \text { s, }
\end{aligned}
$$

$$
\begin{aligned}
T_{d}^{\prime \prime} & =0.03 \mathrm{~s}, \\
T_{q}^{\prime} & =0.03 \mathrm{~s}, \\
H & =6.98 \mathrm{~s} ;
\end{aligned}
$$

and parameters of the additional damping controller are

$$
\begin{aligned}
& T_{1}=5.32 \mathrm{~s}, \\
& T_{2}=0.06 \mathrm{~s}, \\
& T_{3}=0.38 \mathrm{~s}, \\
& K=12.9 .
\end{aligned}
$$

6.2. RTDS Hardware Requirement and Calculation Assignment. RTDS hardware has the following requirement: 10 processors (GPC-PB5) of 2 RACKs and 1 12-channel analog input card (GTAO) are used in the whole model. RTDS is the real time simulation equipment, and the processors must be properly allocated when modeling. To enhance simulation accuracy, small-step (<2 us) RTDS/RSCAD system is used as the carrier of DFIG system model. Each model includes DFIG and PWM frequency converter and transformer. Small-step is set up in the VSC module in the small-step model base. Each VSC module has a corresponding processor (GPC-PB5). So among 10 processors, 6 of them correspond to 6 DFIGs' models, respectively, and the remaining 4 are for controlling calculation and the synchronous generator simulation and the grid simulation.

6.3. Experimental Prototype and Interface of RTDS. The wind farms, the thermal power system, and the AC/DC power transmission system shown in Figure 3 are simulated by RTDS. As the analog state variables, the frequency of the common bus of wind farms, the speed of synchronous generator, and the power-angle are the output from GTAO of RTDS, and they are put into the data collection module of the experimental prototype by the signal cable. To simulate actual 


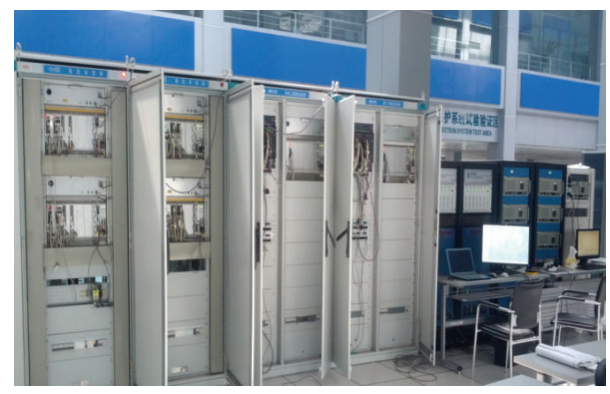

FIGURE 4: Joint debugging of the experimental prototype and RTDS.

fiber channel, the photoelectric conversion module and the $3 \mathrm{~km}$ single-mode fiber are set up in the experimental device. The additional damping control signals are produced after the signals collected from RTDS are processed through the data management module and the algorithm producing module. Then, the additional damping control signals are connected to GTAI of RTDS through profibus and photoelectric module to control the stability of the system.

In Figure 3, the first-order part of DC power transmission system is simulated by RTDS and the controller of DC power transmission system is a special controlling system developed on DPS3000 platform. It is connected with RTDS through signal cable. After the connection, RTDS and the experimental device construct a closed controlling system in which the experimental device is the controller and RTDS is being controlled, as is shown in Figure 4.

\section{Joint Debugging of Experimental Device and RTDS}

7.1. Experiment Analysis of Damping Characteristic. The experiment is described as follows: rectify excitation parameters and active power of the synchronous generator to produce weak damping; set up three-phase transient circuit fault at the common DC-bus to activate low frequency oscillation; and record the speed of the synchronous generator, active power of the wind turbine, stator current, and rotor current.

(1) Record the speed of the synchronous generator and observe the additional damping control. The speed is shown in Figure 5(a) under the condition that the experimental prototype is not put into operation. Compare Figures 5(a) and 5(b) and it is clear that the amplitude of the curve under additional damping control is smaller and smaller, which presents good damping characteristic. This indicates that, under additional damping control, the damping characteristic of the system gets improved.

(2) Record the active power of DFIG and analyze the active power regulation ability of the wind turbine in the transient process. Figure 6(a) shows the real time active power of DFIG without damping control strategy when short circuit occurs; Figure 5(b) shows the active power of DFIG under damping control. Compare two figures and it is seen that when low frequency oscillation occurs in the system, DFIG rectifies its active power according to additional controlling signals sent by the experimental device to activate additional damping control. When the experimental device is not connected, DFIG outputs constant active power only according to the given value and does not provide any damping for the synchronous generator.

(3) Record the stator current and rotor current of the DFIG and observe the variation of current under additional damping control. Figures 6(a) and 6(b) show rotor current of DFIG when the experimental prototype is not put into operation and when it is. Figures 7(a) and 7(b) show the stator current of the DFIG when the experimental prototype is not put into operation and when it is. Compare these four situations and it is found that the rotor current does not show significant change when there is experimental prototype and when there is not. Although the stator current increases substantially when the experimental prototype is available, the current changes within safe range because it is not directly connected with other power electric devices. It indicates that additional damping control would not bring negative effect to the wind turbine and the system.

From the results it is seen that the active power of each wind turbine in the wind farms can be concentrated to be adjusted based on the integrated control platform of the wind farms and the technology of wide-field communication. When the system is working under weak damping, the action of additional damping control is excited to increase the damping of the system and prevents low frequency oscillation. At the same time, there is no negative influence on the wind turbine and the system, which proves that the method is available. In addition, wind-thermal ratio is an important factor influencing the damping effect. If the ratio is too small, the damping effect is limited. Compulsory damping may lead to overload of the rotor.

\subsection{Experimental Analysis of Angle Stability}

7.2.1. Fault Analysis of the Wind Farms. After the large-scale wind farms are connected to the power system, the overall stability of the power system declines greatly. An experiment is carried out to find out reasons. The wind farms in Figure 3 are replaced by a thermal power plant (SG1) of the same level. SG and SG1 constitute a large-scale thermal power plant. Fault simulation is compared between the single thermal power plant and the wind-thermal hybrid power system to see how the wind farms affect the stability of the power system. Assume that short circuit fault occurs on AC (B3B4) for $0.3 \mathrm{~s}$. Simulation results under two power modes are shown in Figures 8(a) and 8(b).

From Figure 8(a), it is seen that, after short circuit fault occurs, two thermal power plants have experienced an abrupt decline of power. The active power of SG and SG1 is reduced to 0.11 p.u., respectively. It suggests that the power decline is shared between two thermal power plants. From Figure 8(b), it is found that, after short circuit fault happens, the power of SG is decreased to 0.22 p.u. but that of the wind farms remains unchanged. It suggests that the power decline occurs only in the thermal power plant rather than both. This is not conductive to the thermal power plant and may result in its power-angle instability. Thus, a coordinated control strategy is proposed to address the power imbalance during the fault. 


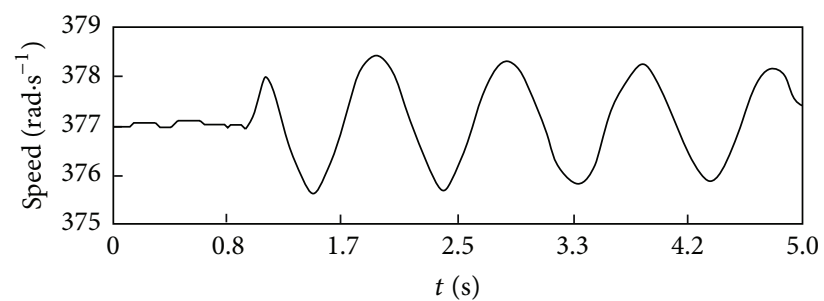

(a) Experimental prototype not put into operation

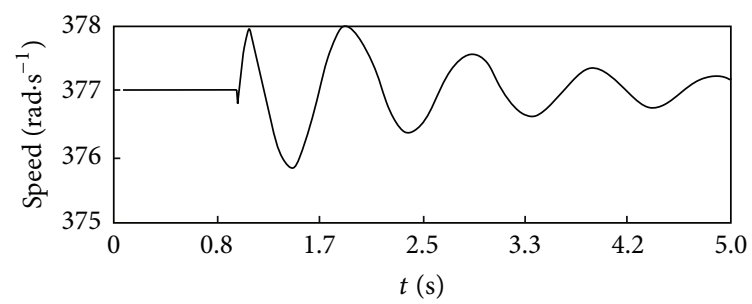

(b) Experimental prototype put into operation

FIGURE 5: The speed of the synchronous generator.

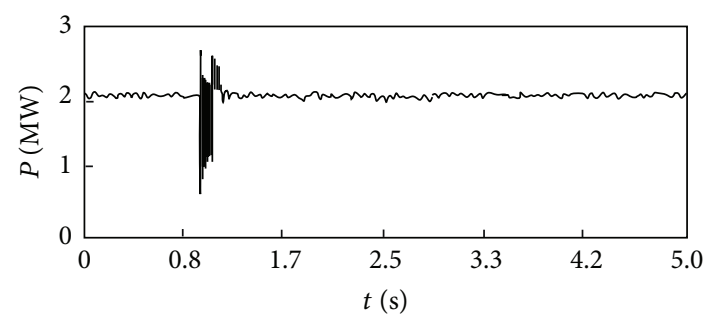

(a) Experimental prototype not put into operation

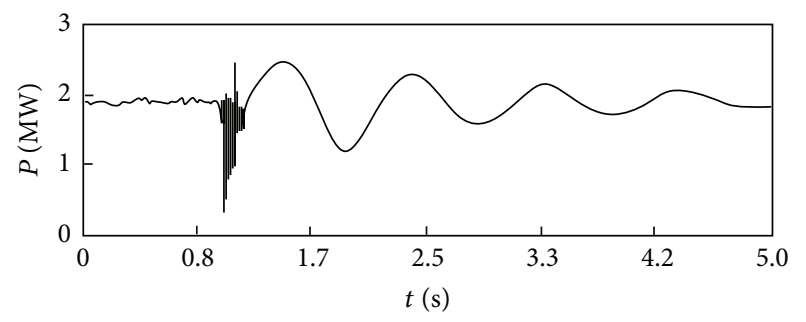

(b) Experimental prototype put into operation

FIGURE 6: Rotor current of the doubly fed generator.

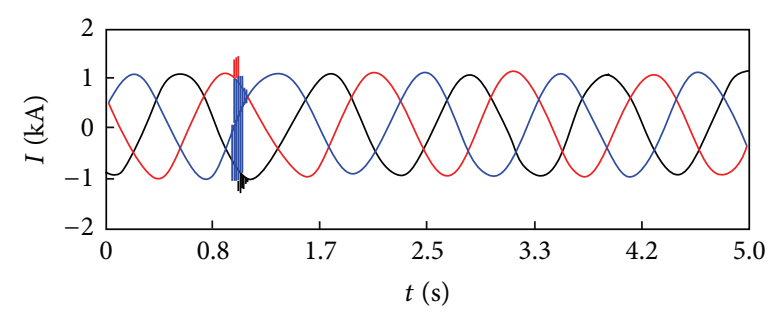

(a) Experimental prototype not put into operation

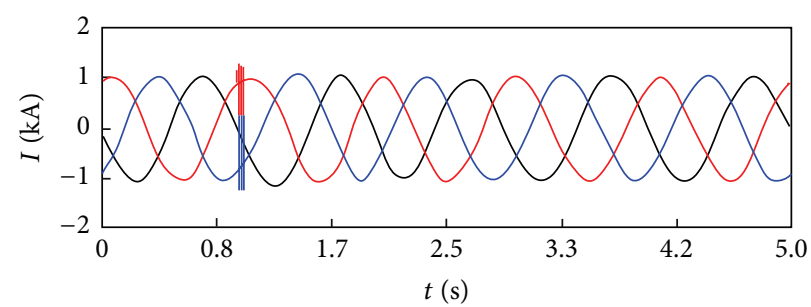

(b) Experimental prototype put into operation

Figure 7: Stator current of DFIG.

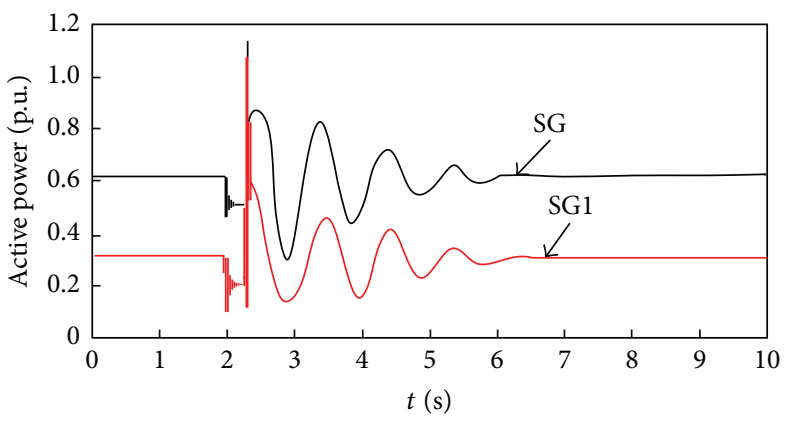

(a) Thermal power plant power

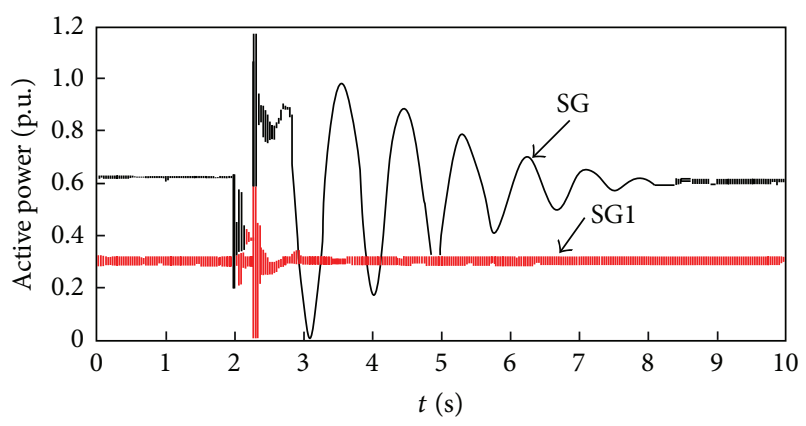

(b) Wind-thermal hybrid power

FIGURE 8: Power comparisons under fault.

7.2.2. Angle Stability under Coordinated Control. In order to test the effectiveness of coordinated control strategy, a short circuit default simulation is carried out based on the experiment in Figure 4. Fault occurs on the AC circuit. Results are shown in Figure 9. Figure 9(a) shows the variation of powerangle of SG due to $0.3 \mathrm{~s}$ fault without the coordinated strategy. It shows that the stability of the synchronous generator is violated. Under the same fault condition, Figure 9(a) shows the variation of power-angle of SG due to $0.3 \mathrm{~s}$ fault with the coordinated strategy. The maximum oscillation of powerangle is $69^{\circ}$, which indicates that the synchronous generator is within its stability.

The duration of fault can reflect how bad the fault is. Thus, the duration is increased to $0.41 \mathrm{~s}$. And the variation of power-angle is shown in Figure $9(\mathrm{c})$. It shows that the maximum oscillation of angle is $79^{\circ}$, which indicates that 


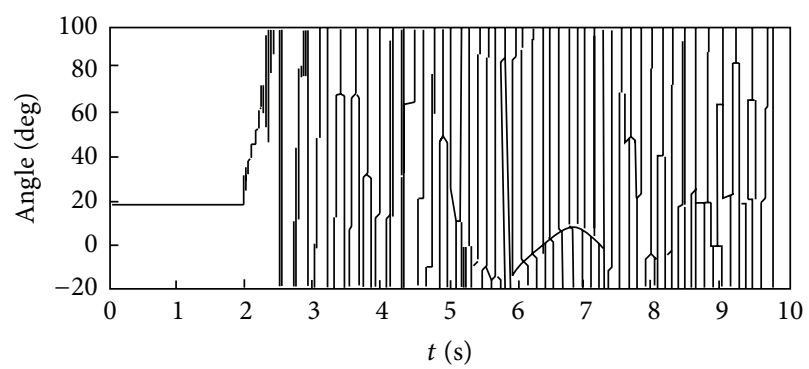

(a) Without coordinated control $t=0.3 \mathrm{~s}$

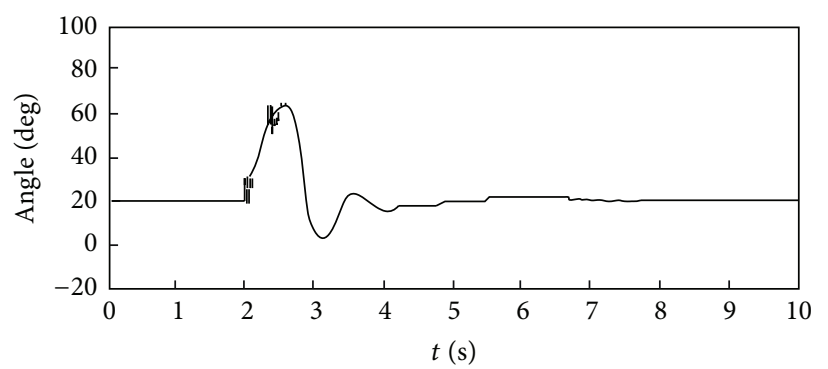

(b) With coordinated control $t=0.3 \mathrm{~s}$

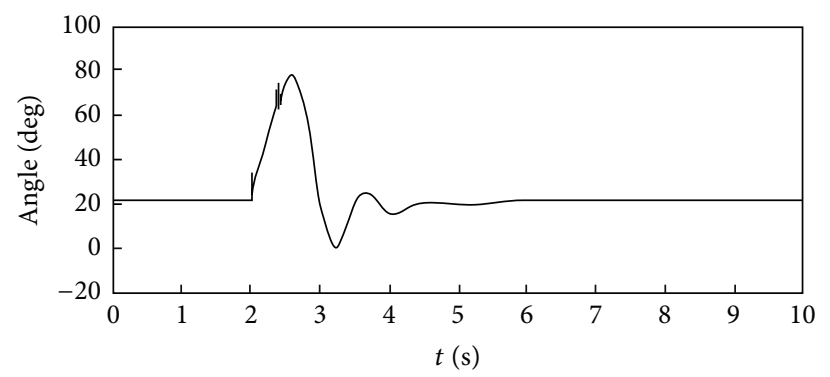

(c) With coordinated control $t=0.41 \mathrm{~s}$

FIGURE 9: Analysis of the influence of coordinated control strategy.

the synchronous generator maintains its stability. Consequently, the coordinated control strategy proposed in this paper is proved to enhance the transient stability of the wind farms thermal hybrid power system.

\section{Conclusion}

Conclusions can be drawn as follows:

(1) The active power and the reactive power of DFIG have quick responses. Under the support of wide-field optical fiber network, doubly fed wind farms can be adjusted quickly.

(2) Quick adjustment of the active power of doubly fed wind farms is accomplished, which can restrain the low frequency oscillation of the thermal power unit and can supply the positive damping to the unit.

(3) Through coordinated control for wind farms and DC power transmission system, the transient stability of the hybrid power system can be enhanced.

(4) The experimental prototype and RTDS are connected for joint debugging. Results show that the experimental prototype can pose significant damping effect on thermal power plant and lower the risk of low frequency oscillation of the grid. The experimental prototype can also enhance the transient stability of hybrid AC/DC power transmission system.

\section{Conflict of Interests}

The authors declare that there is no conflict of interests regarding the publication of this paper.

\section{Acknowledgments}

The authors gratefully acknowledge the support of Science and Technology Project of Henan Province (112101210700), the Introduce Talents Research Fund of Guizhou University (2014-07), the National Natural Science Fund of China (51467003, 61403221), Open Foundation of Key Laboratory of Pulp and Paper Science and Technology of Ministry of Education of China under Grant nos. KF201419 and 08031347, and the Social Development Research Project of Guizhou Province (SY[2011]3081).

\section{References}

[1] S. Wang, D. Yu, and J. Yu, "A coordinated dispatching strategy for wind power rapid ramp events in power systems with high wind power penetration," International Journal of Electrical Power \& Energy Systems, vol. 64, pp. 986-995, 2015.

[2] H. Li, S. Guo, L. Cui, J. Yan, J. Liu, and B. Wang, "Review of renewable energy industry in Beijing: development status, obstacles and proposals," Renewable and Sustainable Energy Reviews, vol. 43, pp. 711-725, 2015.

[3] A. A. Eldesouky, "Security constrained generation scheduling for grids incorporating wind, photovoltaic and thermal power," Electric Power Systems Research, vol. 116, pp. 284-292, 2014.

[4] Y. Zhang, F. Yao, H. H. C. Iu, T. Fernando, and H. Trinh, "Windthermal systems operation optimization considering emission problem," International Journal of Electrical Power and Energy Systems, vol. 65, no. 2, pp. 238-245, 2015.

[5] Y. Yubisui, S. Kobayashi, R. Amano, and T. Sugiura, "Effects of nonlinearity of magnetic force on passing through a critical speed of a rotor with a superconducting bearing," IEEE Transactions on Applied Superconductivity, vol. 23, no. 3, pp. 338-340, 2013. 
[6] B. Basu, A. Staino, and M. Basu, "Role of flexible alternating current transmission systems devices in mitigating grid faultinduced vibration of wind turbines," Wind Energy, vol. 17, no. 7, pp. 1017-1033, 2014.

[7] A. Moharana, R. K. Varma, and R. Seethapathy, "SSR alleviation by STATCOM in induction-generator-based wind farm connected to series compensated line," IEEE Transactions on Sustainable Energy, vol. 5, no. 3, pp. 947-957, 2014.

[8] S.-Y. Yang, Y.-K. Wu, H.-J. Lin, and W.-J. Lee, "Integrated mechanical and electrical DFIG wind turbine model development," IEEE Transactions on Industry Applications, vol. 50, no. 3, pp. 2090-2102, 2014.

[9] H. Hinz, B. Zuber, and J. Kilz, "Development of a hybrid power generation system," in Proceedings of the International Exhibition and Conference for Power Electronics, Intelligent Motion, Renewable Energy and Energy Management (PCIM Europe '14), pp. 651-658, IEEE, Nuremberg, Germany, May 2014.

[10] R. Zhu, Z. Chen, X. Wu, and F. Deng, "Virtual damping flux-based LVRT control for DFIG-based wind turbine," IEEE Transactions on Energy Conversion, vol. 23, no. 1, pp. 186-192, 2015.

[11] T. Surinkaew and I. Ngamroo, "Coordinated robust control of DFIG wind turbine and pss for stabilization of power oscillations considering system uncertainties," IEEE Transactions on Sustainable Energy, vol. 5, no. 3, pp. 823-833, 2014.

[12] S. Nouri, E. Babaei, and S. H. Hosseini, "A new AC/DC converter for the interconnections between wind farms and HVDC transmission lines," Journal of Power Electronics, vol. 14, no. 3, pp. 592-597, 2014.

[13] Y. Li, Z. Zhang, Y. Yang, Y. Li, H. Chen, and Z. Xu, "Coordinated control of wind farm and VSC-HVDC system using capacitor energy and kinetic energy to improve inertia level of power systems," International Journal of Electrical Power \& Energy Systems, vol. 59, pp. 79-92, 2014.

[14] A. Rabiee, A. Soroudi, and A. Keane, "Information gap decision theory based OPF with HVDC connected wind farms," IEEE Transactions on Power Systems, vol. 30, no. 6, pp. 3396-3406, 2014.

[15] I. Erlich, C. Feltes, and F. Shewarega, "Enhanced voltage drop control by VSC-HVDC systems for improving wind farm fault ridethrough capability," IEEE Transactions on Power Delivery, vol. 29, no. 1, pp. 378-385, 2014.

[16] A. Rabiee and A. Soroudi, "Stochastic multiperiod OPF model of power systems with HVDC-connected intermittent wind power generation," IEEE Transactions on Power Delivery, vol. 29, no. 1, pp. 336-344, 2014.

[17] K. E. Okedu, S. M. Muyeen, R. Takahashi, and J. Tamura, "Effectiveness of current-controlled voltage source converter excited doubly fed induction generator for wind farm stabilization," Electric Power Components and Systems, vol. 40, no. 5, pp. 556574, 2012.

[18] A. A. Elserougi, A. S. Abdel-Khalik, A. M. Massoud, and S. Ahmed, "A new protection scheme for HVDC converters against DC-side faults with current suppression capability," IEEE Transactions on Power Delivery, vol. 29, no. 4, pp. 15691577, 2014.

[19] J.-H. Lee, T.-H. Kim, G.-H. Kim, S. Heo, M. Park, and I.-K. Yu, "RTDS-based modeling of a $100 \mathrm{MW}$ class wind farm applied to an integrated power control system," in Proceedings of the IEEE Vehicle Power and Propulsion Conference (VPPC '12), pp. 14411443, Seoul, Republic of Korea, October 2012. 


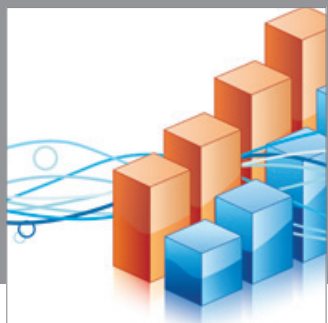

Advances in

Operations Research

mansans

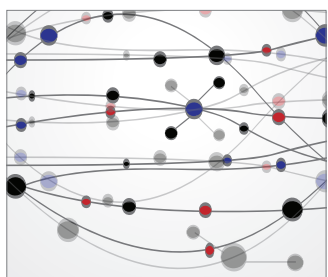

The Scientific World Journal
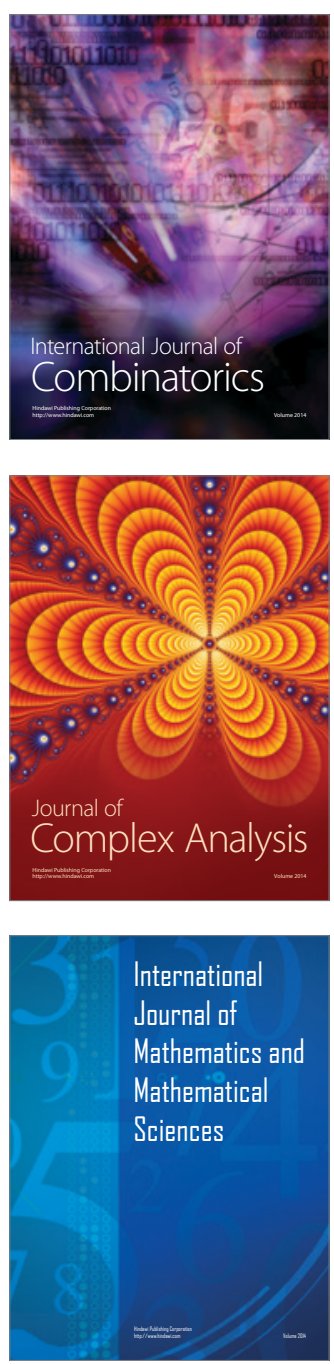
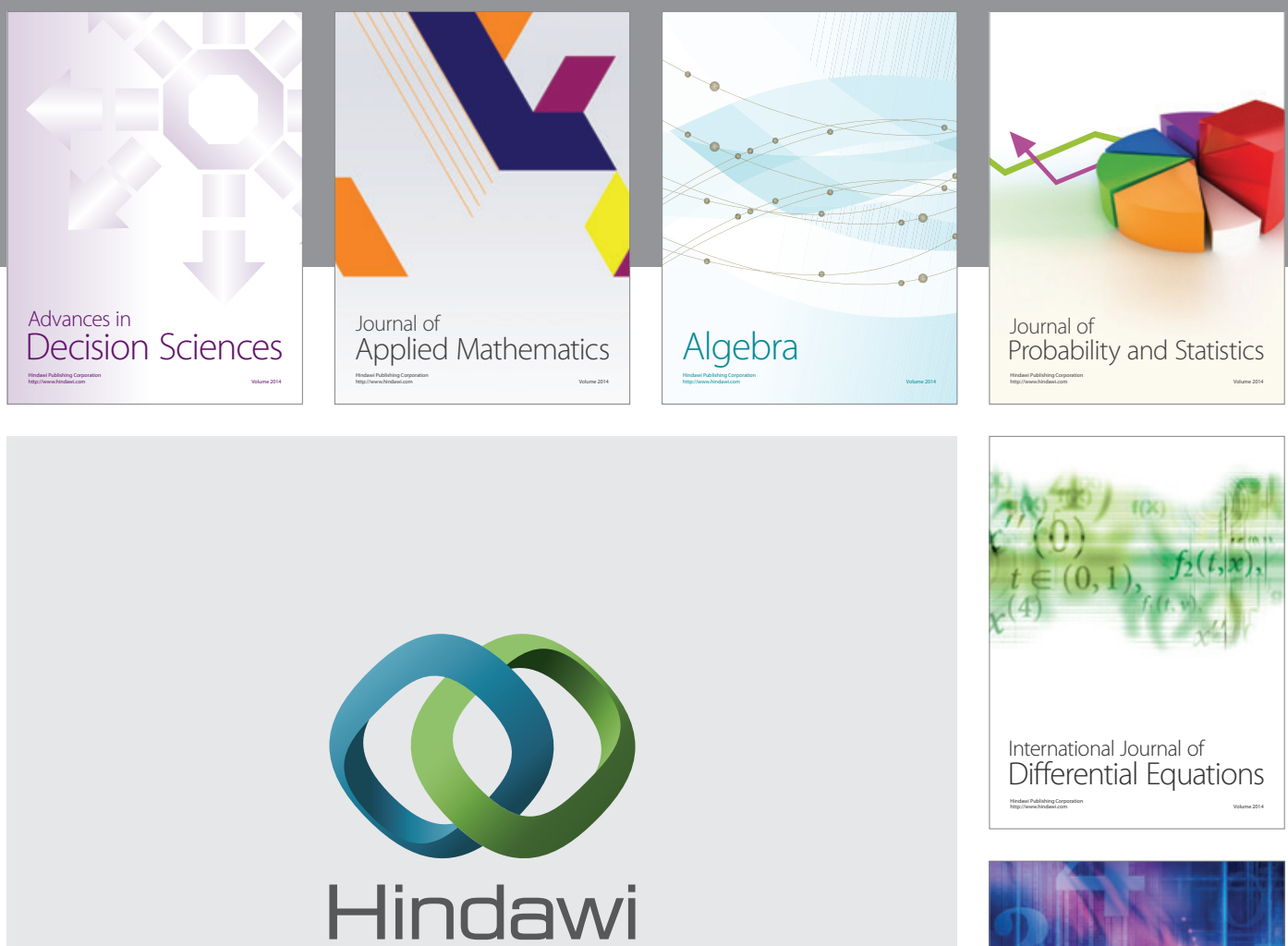

Submit your manuscripts at http://www.hindawi.com
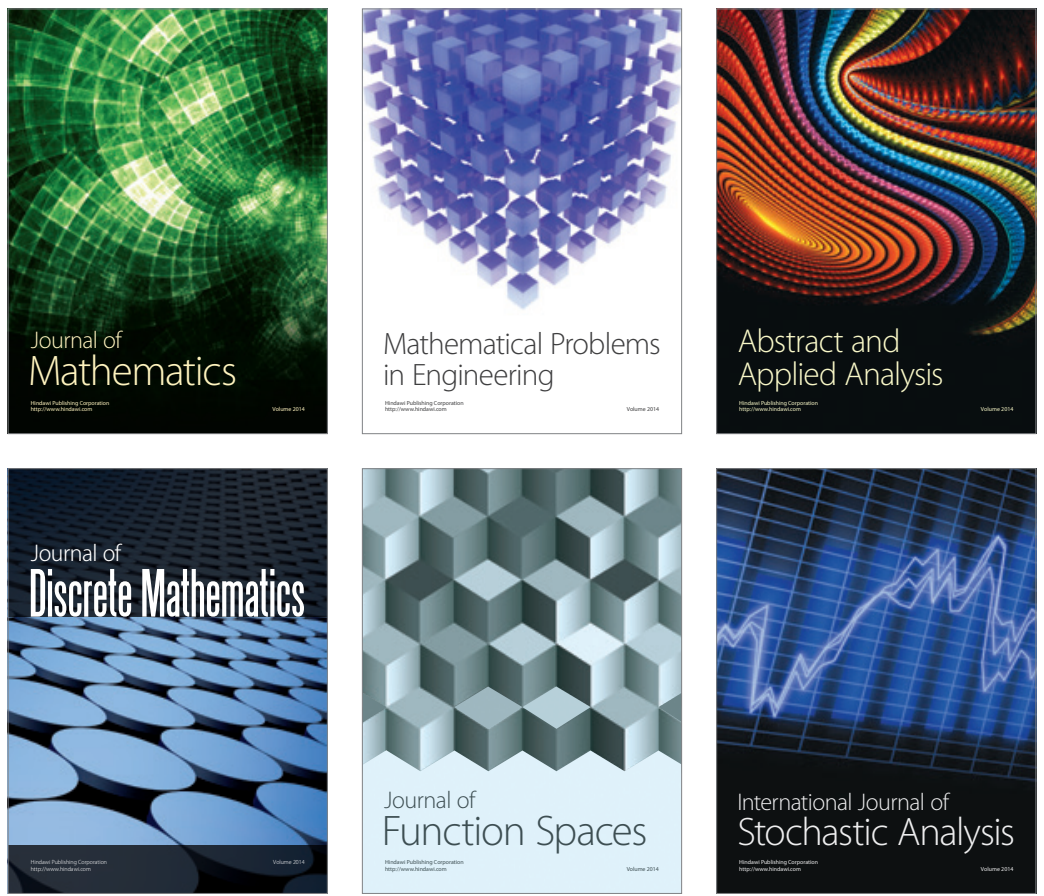

Journal of

Function Spaces

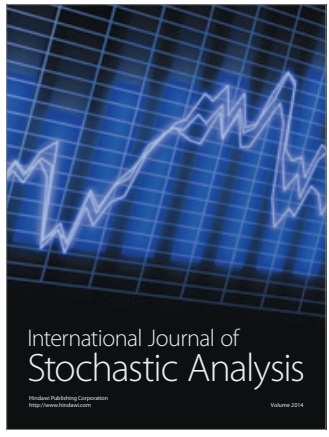

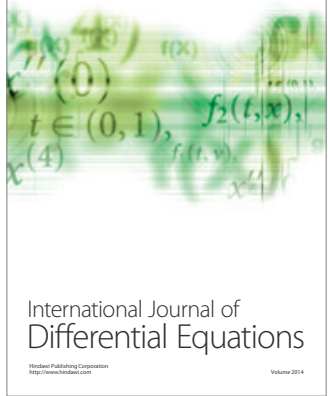
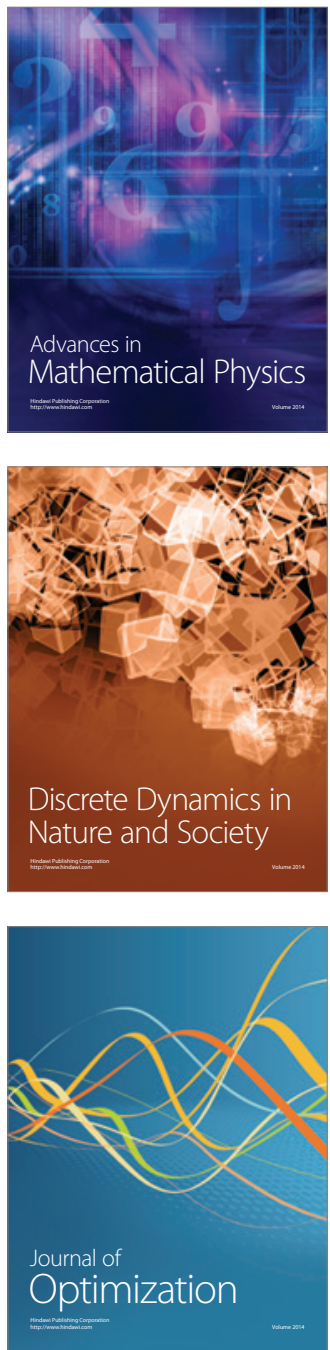